\title{
OS ESTUDOS SOBRE A CULTURA DA ESCOLA: FORMA, TRADIÇÕES, COMUNIDADE, CLIMA, PARTICIPAÇÃO, PODER*
}

\author{
Ana Maria Falsarella ${ }^{1}$
}

\begin{abstract}
RESUMO: Este trabalho versa sobre temas relacionados à cultura de instituiçôes escolares em seu funcionamento cotidiano: tradição escolar, clima organizacional, participação e partilha do poder, conceito de comunidade. Trata-se de uma exploração teórica, sem pretensão de esgotar a literatura a respeito dos assuntos. Situa-se no campo de estudos da Sociologia da Educação. Visa contribuir para clarear conceitos significativos relacionados aos estudos sobre a escola, levantar pontos para reflexão e sugerir subsídios para análises de pesquisas empíricas desenvolvidas na área da educação. Destaca que estudar a escola em seu funcionamento cotidiano é desafio difícil para o pesquisador, mas que traz ricas contribuiçóes para a escola e para os estudos acadêmicos.
\end{abstract}

Palavras-chave: Cultura escolar. Forma escolar e tradiçóes. Clima organizacional. Participação e partilha do poder. Conceito de comunidade.

\section{STUDIES ON SCHOOL CULTURE: \\ FORM, TRADITIONS, COMMUNITY, CLIMATE, PARTICIPATION, POWER}

ABSTSRACT: This work deals with themes related to the culture of school institutions and daily functioning: school traditions, organizational climate, power participation and sharing, community concept. This is a theoretical exploration that does not aim to exhaust the literature on the subject. Sociology of Education is the field of study this paper belongs to. It aims to help clarifying significant concepts related to studies about school, by raising points for reflection and offering subsidies to analyze empirical research developed in the area of education. Important to note that school culture and its daily functioning is a challenging theme to researchers, but brings valuable contributions to school and to academic studies.

Keywords: School culture. School form and traditions. Organizational climate. Participation and power sharing. Community concept.

\footnotetext{
*Estudo vinculado ao Grupo de Pesquisa Organização e Gestão de Instituições Educacionais. Espelho CNPq. Disponível em: <http://dgp.cnpq.br/dgp/espelhogrupo/3918268240358300>. Agência fomentadora: Fundação Nacional de Desenvolvimento do Ensino Superior Particular (FUNADESP).

${ }^{1}$ Universidade de Araraquara (UNIARA), Programa de Pós-graduação em Processos de Ensino, Gestão e Inovação - Araraquara (SP), Brasil. E-mail: anafalsarella@gmail.com

Doi: 10.1590/ES0101-73302018182991
} 


\section{ÉTUDES SUR LA CULTURE DE L'ÉCOLE: FORME, TRADITIONS, COMMOUNATÉ, CLIMAT, PARTICIPATION, POUVOIR}

RÉSUMÉ: Ce travail porte sur les questions liées à la culture des établissements d'enseignement et leur fonctionnement quotidien: les traditions scolaires, le climat scolaire, la participation et partage du pouvoir, le concept de communauté. Cette exploration théorique ne cherche pas à épuiser la littérature sur ce sujet. Il se situe dans le domaine des études de sociologie de l'éducation. On vise à dégager des concepts importants liés aux études sur l'école, soulever des points de réflexion et offrir l'aide pour analyser les recherches empiriques sur l'éducation. Il importe de signaler que l'étude de l'école et son fonctionnement quotidien constitue un défi pour le chercheur, mais aussi apporte une riche contribution à l'école et les études universitaires.

Mots-clés: Culture scolaire. Forme scolaire et traditions. Climat scolaire. Participation et partage du pouvoir. Concept de communautaire.

\section{Introdução}

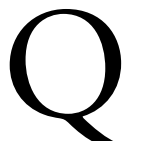

uem se propóe a estudar a escola encontrará um campo praticamente inesgotável, com ampla possibilidade quanto a áreas, linhas de investigação e autores. Os estudos sobre a escola envolvem temas múltiplos e igualmente relevantes que concorrem para compor o panorama da cultura escolar.

Estudar a escola implica, outrossim, engajar-se na discussão de questôes relacionadas à democratização das oportunidades educacionais. É comum que se relacione as desigualdades nas aprendizagens à expansão de oportunidades de acesso e de permanência na escola, o que constitui uma visão reducionista dos problemas da educação escolar.

A extensão de oportunidades educacionais a toda a população, por sua vez, veio colocar a necessidade de construção de uma nova concepção de escola, desgarrada do conceito de excelência do passado (BEISIEGEL, 2005).

De acordo com Nóvoa (1999), nos anos 1970, estudos da Sociologia “"revelaram de que forma as variáveis sociais, culturais e familiares interferem no sucesso dos alunos", "sublinharam que as diferenças entre as crianças que iniciam a escolaridade só se transformam em desigualdades devido à estrutura e ao funcionamento do sistema educativo", porém, "subestimaram a influência das variáveis escolares e dos processos internos aos estabelecimentos de ensino" (NÓVOA, 1999, p. 15). 
Para escapar ao vaivém entre uma percepçáo micro (interna à escolar) e uma visão macro (unicamente social), o autor propóe a realização de estudos em nível de mesoabordagem dos fenômenos escolares, conduzindo-se à percepçáo de que os problemas são engendrados tanto dentro dos muros escolares quanto na própria sociedade, em processo de mútua dependência.

Partindo de consideraçóes sobre a forma escolar e a cultura escolar, no presente texto cuida-se especialmente do seguinte: tradiçóes escolares, clima organizacional, participaçáo e partilha do poder e, por fim, conceito de comunidade. Os assuntos são explorados separadamente com a finalidade didática de expô-los com clareza e objetividade. No entanto, na análise da prática escolar, eles se mostram indissociáveis. Na seleção dos aportes teóricos houve o cuidado de garantir a presença de alguns autores que, a nosso ver, são referências: Pereira (1967), Rockwell (1986), Mercado (1986), Azanha (1995), Hargreaves (1998), Viñao Frago (1998), Brunet (1999), Gimeno Sacristán (1999), Vincent et al. (2001), Enguita (2003) e Barroso (2012), embora outros autores também sejam citados e consciente de que não haveria espaço para tantos outros igualmente relevantes ${ }^{2}$.

O trabalho, de caráter teórico-exploratório, se situa no ramo dos estudos contemporâneos da Sociologia da Educação. Com ele, temos por objetivos:

- Contribuir para clarear conceitos significativos relacionados à cultura escolar;

- Levantar pontos para reflexão a respeito dos estudos sobre a escola;

- Sugerir subsídios para análises de pesquisas empíricas desenvolvidas na área da educação.

\section{Relevância}

A globalização dos mercados foi incrementada pela explosão científico-tecnológica ocorrida no século XX. Provocou a remodelação do sistema de produção industrial, o desenvolvimento dos meios de transporte, o avanço nas telecomunicações e a consequente aceleração da disseminação de informações e de circulação de mercadorias. Essas seriam as principais características do "rápido, comprimido, complexo e incerto mundo pós-moderno" (HARGREAVES, 1998, p. 10). As grandes marcas da pós-modernidade, de acordo com esse autor, são a impermanência e a instabilidade observadas no atual momento histórico. Pontos de apoio, como valores e normas que, anteriormente, garantiam ao ser humano segurança e continuidade, desaparecem. $\mathrm{O}$ alto grau de indeterminação leva a crises nos campos econômico, político e social, as quais atingem tanto as pessoas quanto as instituiçóes. 
Nos debates sobre as relaçóes econômicas, políticas e sociais do mundo contemporâneo, a educação escolar mantém sua relevância em virtude do vínculo que ainda apresenta com a estrutura capitalista, tida agora como um dos meios de formar sujeitos capazes de operar no mundo globalizado. Intenso movimento de reformas educacionais resultou da emergência da chamada pós-modernidade, sendo que, desde o início dos anos 1990, tem aumentado o interesse sobre estudos e debates em torno da educação, tanto no que refere à organização, gestão e financiamento, quanto no que tange à dinâmica intraescolar (WARD, 1998).

No que tange às repercussóes das reformas na dinâmica intraescolar, vale alertar para o que, em 1976, Tragtenberg já chamava de pedagogia burocrática, relativa ao controle burocrático sobre o trabalho docente, que ocorre principalmente por meio da aplicação dos exames unificados. Segundo o autor, mais que os programas, sáo os exames que definem a pedagogia do docente, sendo que o objetivo da pedagogia burocrática não é o enriquecimento intelectual do aluno, mas seu êxito no sistema de exames (TRAGTENBERG, 2016).

No entanto, como campo de luta ideológica, a escola (e os docentes) não se submete sem resistência. As mudanças propostas para a educação se deparam com a manutenção de uma forma escolar sedimentada, que dá permanência histórica à escola, e que começa a se instituir nos séculos XVI e XVII, instaurando um lugar e um tempo específico para que a relação pedagógica aconteça: em um espaço fechado e ordenado para a realizaçáo dos deveres, dentro de um tempo cuidadosamente regulado - a escola. Trata-se do modo escolar de socializaçấo e de formaçấo de cidadãos que se torna dominante nas formaçóes sociais modernas e que, gradativamente, vai se estendendo a todas as crianças e jovens. $\mathrm{O}$ que aprendem as novas geraçóes e a que determinadas regras obedecem ganha uma importância fundamental. A forma escolar permite compreender as características comuns das práticas escolares em todas as instituiçóes e as nuances que assumem em cada instituição. Permite, outrossim, compreender as relaçóes entre a educação escolar e outras formas sociais de formação dos sujeitos, uma vez que "ao mesmo tempo em que transmite saberes e conhecimentos, a escola está fundamentalmente ligada a formas de exercício do poder" (VINCENT et al., 2001, p. 17). Por meio dela há a aprendizagem das relaçóes de poder dominantes na sociedade. A forma escolar se caracteriza por um conjunto coerente de traços, tais como:

A constituição de um universo separado para a infância, a importância das regras na aprendizagem, a organizaçáo racional do tempo; a multiplicação e a repetição de exercícios, cuja única função consiste em aprender e aprender conforme as regras, ou, dito de outro modo, tendo por fim seu próprio fim (VINCENT et al., 2001, p. 37-38).

A fabricação da excelência escolar e sua repercussão nas classificações escolares a que os alunos estão sujeitos acabam por situá-los na sociedade para além do 
tempo e do domínio escolar. Segundo esses autores, o modo de socialização escolar é indissociável da natureza escritural dos saberes, ou seja, a escola é, por excelência, o lugar de aprendizagem da língua escrita: "A forma escolar de relaçóes sociais é a forma social constitutiva do que se pode chamar uma relação escritural-escolar com a linguagem e com o mundo" (VINCENT et al., 2001, p. 34-35).

Em síntese, com a forma escolar, a infância e a juventude passam a constituir uma categoria particular de sujeitos distintos dos outros sujeitos sociais, e suscetíveis de um tratamento particular: a educação escolar. Uma vez na escola, separados dos outros sujeitos em um espaço fechado, constroem saberes e relaçóes com a linguagem, com o outro e com o mundo, aprendendo formas sociais específicas que correspondem a modalidades do poder.

A despeito das características comuns a todas as instituiçóes escolares, cada uma delas tem seu jeito peculiar de lidar com os saberes e as relaçóes sociais. E aqui se apresenta a relevância dos estudos sobre a cultura escolar e temas correlatos, uma vez que possibilitam apreender as variantes que a forma escolar toma em diferentes instituições de ensino.

\section{Cultura escolar}

Uma abordagem sociológica da escola não pode ignorar seu aspecto cultural, sendo que diferentes perspectivas teóricas se apresentam. De modo esquemático, Barroso (2012) identifica três perspectivas de abordagem (Quadro 1).

\section{Quadro 1}

Perspectivas de abordagem sobre a cultura escolar.

\begin{tabular}{|l|c|}
\hline Perspectiva & Concepçáo de cultura escolar \\
\hline Funcionalista & $\begin{array}{c}\text { Traz o sentido mais geral da cultura que é veiculada por meio da escola, a } \\
\text { qual é vista como simples transmissora de uma cultura definida e produzida } \\
\text { exteriormente e que se traduz nos princípios, finalidades e normas postas pelo } \\
\text { poder dominante (político, social, econômico, religioso) como o substrato do } \\
\text { processo educativo e da aculturação das novas geraçóes. }\end{array}$ \\
\hline Estruturalista & $\begin{array}{c}\text { É a cultura produzida pela forma escolar de educaçáo existente em dada } \\
\text { sociedade, por meio de modelos de formas e estruturas, tais como planos } \\
\text { de estudos, disciplinas escolares, modos de organização pedagógica, meios } \\
\text { auxiliares de ensino, entre outros. }\end{array}$ \\
\hline Interacionista & $\begin{array}{c}\text { Diz respeito à cultura de cada escola em particular (e como instituição global); } \\
\text { é produzida pelos atores organizacionais nas relaçóes de uns com os outros, } \\
\text { com o espaço e com os saberes, mas dentro dos limites estabelecidos pelos } \\
\text { esquemas globais de funcionamento das escolas na sociedade. }\end{array}$ \\
\hline
\end{tabular}

Fonte: elaborado pela autora com base em Barroso (2012). 
Cabe destacar que os termos "cultura escolar" e "cultura da escola" são usualmente considerados como portadores do mesmo significado básico relacionado à cultura interna de cada instituição e é nesse sentido que aqui são tomados, considerando a perspectiva interacionista (BARROSO, 2012). No entanto, há autores que fazem uma diferenciação entre eles. Para Forquin (1993), a cultura da escola diz respeito ao mundo interno da escola, à produção e gestão de símbolos, ritos e linguagens, bem como aos modos de regulação e transgressão instituídos. Já, a cultura escolar se refere ao conjunto de conteúdos cognitivos e simbólicos socialmente valorizados, selecionados e transmitidos deliberadamente em todas as escolas. Entendemos que a definição de cultura de escola pode ser associada à visão interacionista, enquanto a de cultura escolar estaria mais associada às visóes funcionalista e estruturalista, nos termos de Barroso (2012).

Escolas são instituiçóes históricas e culturais que se assemelham na arquitetura e na estrutura organizacional. Ao mesmo tempo, cada escola é terreno diferenciado, em que subgrupos sociais com diferentes interesses se definem mutuamente, caracterizando sua cultura, dentro de determinado tempo, espaço e local. Estudar a rede de significados que compóe a cultura escolar permite a identificação dos mitos, crenças e valores que direcionam determinado grupo-escola, construídos ao longo do tempo pela história cotidiana vivenciada por seus membros, e que identificam cada escola em particular. Neste texto adotou-se a definição de cultura escolar apresentada por Viñao Frago (1998, p. 68-69):

A cultura escolar é vista como um conjunto de teorias, princípios ou critérios, normas e práticas sedimentadas ao longo do tempo no seio das instituiçóes educativas. Trata-se de modos de pensar e atuar que proporcionam estratégias e pautas para organizar e levar a classe, interatuar com os companheiros e com outros membros da comunidade educativa e integrar-se à vida cotidiana do centro docente. Tais jeitos de pensar e atuar constituem ocasionalmente rituais e mitos, mas sempre se estruturam em forma de discursos e açôes que, junto com a experiência e formaçáo do professor, lhe servem para levar a cabo sua tarefa cotidiana.

Os membros de uma instituição escolar partilham experiências de condutas, crenças, emoções, valores, formas de compreensão e, também, conflitos e desacordos, que os caracterizam como grupo. De acordo com Gimeno Sacristán (1999), é o caráter de comunháo que cria o contexto e regula as atividades do grupo. Assim, é a natureza compartilhada das açóes que gera a cultura da escola, e não experiências individuais não transferidas. Além da experiência proporcionada a seus próprios agentes, açôes compartilhadas produzem padróes sociais (rotinas, regras, formas de saber fazer) que são utilizados não só no momento de sua produção, como também em ações futuras. Portanto, não formam um simples passado 
ao qual se olha como algo cristalizado. Pelo contrário, têm continuidade temporal, continuam sendo operacionais e organizando as açóes dos sujeitos que as compartilham, abrindo-se para os novos membros que passam a fazer parte do grupo.

\section{Tradições escolares}

A cultura compartilhada significa que tradiçôes foram acumuladas. As tradiçôes são entendidas como modelos educativos ou "corpos consistentes de pensamento e de prática vinculados a determinados valores" (GIMENO SACRISTÁN, 1999, p. 94), o que não significa negar a autonomia de ação dos sujeitos, pois o mundo das regras não é estrutura imutável que impossibilita açôes inovadoras. "A liberdade penetra o mundo das determinações e o recompóe constantemente", afirma Gimeno Sacristán (1999, p. 75). Se tirarmos da tradição o caráter de testamento sagrado, ela se mostrará como um rico depósito de possibilidades do qual podemos sacar materiais conforme a necessidade. A existência de um clima aberto que permite a crítica e a permanente reconstrução do legado recebido é condição para a superação do imobilismo.

O difícil desafio da pedagogia moderna, de acordo com esse autor, é harmonizar as duas linhas básicas de ação, como formas concomitantes de continuidade e de criatividade: reproduzir tradições valiosas e depurar e melhorar as que deixam de ter utilidade. Podemos, então, falar em dois ciclos com relação à tradiçâa: ciclo inovador e ciclo reprodutor. A percepção de que o ciclo reprodutor já não serve ocorre quando surgem novas condiçôes sociais ou culturais às quais as práticas existentes já não conseguem responder. No entanto, não se pode falar em alternância. No mais das vezes acontece que ciclos inovadores convivem com ciclos reprodutores, criando contradiçóes que estimulam conflitos e divergências, que tanto podem provocar avanços quanto retrocessos.

\section{O clima organizacional}

Embora proveniente de estudos mais antigos do que os referentes à cultura escolar, o clima da escola passou a ser visto como um dos elementos constituintes da cultura da instituição, ou como uma "manifestação de superfície", de acordo com Mafra (2003, p. 116). Segundo essa autora, os estudos mais recentes sobre cultura organizacional da escola se confundem com estudos mais antigos incluídos sob a rubrica de clima da escola. Apoiando-se em Schein (1985) e Weller (1966), ela caracteriza o clima ou atmosfera escolar, como "um sentimento geral afinado com o estabelecimento, favorecendo o bom relacionamento e a identificação institucional necessária ao funcionamento adequado da instituição" (MAFRA, 2003, p. 115), sendo que o elemento central para identificar o clima predominan- 
te na instituição, engendrado que é nas relaçóes de autoridade e poder circulantes, é o "tom emocional” (MAFRA, 2003, p. 116).

Brunet (1999) também compreende o clima escolar como a percepção dos atores com relação à atmosfera de trabalho reinante no interior da escola. O clima escolar tem, para ele, íntima relação com as relaçôes estabelecidas na escola entre as lideranças e os demais atores. $\mathrm{O}$ autor traça um retrato dos diferentes tipos de clima que afetam a organização escolar, assentados em dois polos de uma mesma escala contínua, designados como fechado (muito autoritário) e aberto (muito participativo). Cada um desses dois tipos, por sua vez, compreende duas subdivisóes, caracterizadas no Quadro 2.

Brunet (1999) destaca que o clima organizacional é multidimensional e percebido, ao mesmo tempo, de forma consciente e inconsciente por seus membros, de forma que todos têm influência em sua composição. "São os atores que fazem da organização aquilo que ela é” (BRUNET, 1999, p. 125).

\section{Quadro 2}

Clima escolar: tipos característicos.

\begin{tabular}{|c|c|c|}
\hline \multirow{2}{*}{$\begin{array}{l}\text { Clima } \\
\text { de tipo } \\
\text { autoritário }\end{array}$} & $\begin{array}{c}\text { Categoria } 1 \\
\text { Autoritarismo } \\
\text { explorador }\end{array}$ & $\begin{array}{l}\text { Decisôes são tomadas no topo da organização e transmitidas } \\
\text { aos professores sem comentários. O trabalho e as interaçóes } \\
\text { desenvolvem-se numa atmosfera de desconfiança, } \\
\text { descontentamento, receio, ameaças, indiferença e, raramente, } \\
\text { de recompensas. }\end{array}$ \\
\hline & $\begin{array}{c}\text { Categoria } 2 \\
\text { Autoritarismo } \\
\text { benévolo }\end{array}$ & $\begin{array}{l}\text { A maior parte das decisões e o processo de controle são } \\
\text { centralizados no topo da hierarquia, mas, por vezes, há } \\
\text { alguma delegação de poderes com a participaçáo dos níveis } \\
\text { intermédios e inferiores. As interaçôes são estabelecidas com } \\
\text { precauçáo e os métodos utilizados para motivar os professores } \\
\text { são recompensas e, por vezes, penalidades. }\end{array}$ \\
\hline \multirow{2}{*}{$\begin{array}{l}\text { Clima } \\
\text { de tipo } \\
\text { participativo }\end{array}$} & $\begin{array}{l}\text { Categoria } 3 \\
\text { De caráter } \\
\text { consultivo }\end{array}$ & $\begin{array}{l}\text { As decisôes gerais são tomadas no topo, mas é permitida uma } \\
\text { participação em diversos níveis organizacionais. Para motivar } \\
\text { os professores são utilizadas recompensas, puniçóes ocasionais } \\
\text { e a possibilidade de participação. As interaçốes desenvolvem- } \\
\text { se moderadamente, muitas vezes com um nível de confiança } \\
\text { bastante elevado. O controle é delegado de cima para baixo, } \\
\text { com forte sentido de responsabilidade, tanto nos escalóes } \\
\text { superiores como nos inferiores. }\end{array}$ \\
\hline & $\begin{array}{c}\text { Categoria } 4 \\
\text { Participação } \\
\text { do grupo }\end{array}$ & $\begin{array}{l}\text { O processo de tomada de decisões está disseminado por toda } \\
\text { a organização, integrado aos diferentes níveis hierárquicos. Os } \\
\text { professores são motivados pela participação, pelo envolvimento, } \\
\text { pela melhoria dos métodos de trabalho e pela avaliação em } \\
\text { funçáo dos objetivos. O controle é exercido por todos os níveis } \\
\text { da escala hierárquica, uma vez que todos os membros unem } \\
\text { esforços para atingir os fins da organização. As relaçôes entre a } \\
\text { direção e os demais atores são amistosas e de confiança. }\end{array}$ \\
\hline
\end{tabular}

Fonte: elaborado pela autora com base em Brunet (1999). 


\section{Participação e partilha de poder}

O principal interlocutor aqui tomado foi Enguita (2003). Em estudo sobre a gestão em centros de ensino de Madri, o autor comenta a atitude dos professores com relação à participaçáo. Em princípio, a maioria concorda com a positividade da ideia, mas ela coincide pouco com o pensamento contido no discurso oficial. Com relação à participação dos pais, por exemplo, os professores revelam o desejo nada oculto de que esses atuem como um braço do poder da congregaçáo docente fora dos muros da escola. Embora os docentes náo se oponham frontalmente à participação dos pais e de outros segmentos não docentes nas decisóes escolares, no fundo incomodam-se com o fato de exercerem uma das poucas profissóes passíveis ao controle e à ingerência externa.

Para Enguita (2003), o professorado, preso na armadilha das subprofissóes, tenta defender sua posição de grupo perante seus empregadores (em geral, a administração pública) e seu público (alunos e pais). O autor aplica, em seu trabalho, a concepção de feixe social, do sociólogo inglês Frank Parkin (1931-2011). Explicado da seguinte forma: os grupos privilegiados, apoiados em práticas legalistas (uma vez que são eles que fazem as leis) exercem um feixe de exclusão para baixo, pressionando os grupos que lhes são subordinados; em resposta, os grupos subordinados, apoiados em práticas de mobilização coletiva, exercem um feixe de usurpação para cima sobre os grupos dominantes. O natural é que os grupos exerçam uma combinação de ambos, denominado de feixe dual. São, ao mesmo tempo, grupos exploradores e explorados, embora não no mesmo grau. No caso dos professores, eles necessitam usurpar competências dos centros de poder e excluir pais e alunos das competências que lhes são próprias. Assim, os professores exercem um feixe de usurpação com relação à superior administração ao demandar maior democratização e autonomia nas decisóes escolares. E exercem um feixe de exclusão com relação à clientela escolar em nome das competências peculiares atinentes à profissão docente.

Isso tudo representa o movimento de identificação com o restante dos trabalhadores e, ao mesmo tempo, de diferenciar-se deles. Ao exigir da administração a democratização e a autonomia, os professores necessitam da solidariedade dos pais e dos alunos, identificando-se com eles dentro da categoria comum de trabalhadores. Quando o problema passa a ser a defesa de suas competências perante os pais, impóe-se buscar a identidade profissional que situe o grupo acima de seu público.

Vale um parêntese para uma rápida explicação sobre a (semi)profissão docente. A tradição inicial na sociologia das profissões, esclarece Sarmento (1994), fundada numa visão estática, fixava um conjunto de atributos para considerar um grupo ocupacional como profissional (longa escolaridade, controle na admis- 
são e liberdade de exercício na profissão, a existência de um código de conduta profissional). Foi a aplicação dessas categorias ao grupo ocupacional docente que permitiu considerar os professores como semiprofissionais, tal como enfermeiros e assistentes sociais, visto que a sua formação é mais reduzida, o seu status está menos legitimado e têm menor autonomia com relação à supervisão e ao controle social do que profissóes mais definidas.

Mais recentemente emergiu um conceito não estático de profissão, que considera a profissionalização como decorrência de um processo social. Assim, segundo Popkewitz (1997), não há um significado universal intrínseco para a palavra profissão, pois ela envolve um conceito de construção social, isto é, só adquire sentido na sua relação com as condiçóes sociais e cenários institucionais a que as pessoas estão sujeitas. Uma profissão pode ser definida pela autonomia, pelo conhecimento técnico e pela ética de trabalho que envolve um grupo ocupacional, pode identificar um grupo altamente formado e especializado, que corresponde à confiança pública, ou, ainda, ser vista como categoria social que concede posição e privilégio a determinados grupos.

\section{O conceito de comunidade}

No senso comum vigente entre os profissionais da educação, comunidade tem sido entendida como a populaçáo usuária da escola, que vive em seu entorno. Mas, o significado do termo não é tão simples. Para iniciar a abordagem (destacando que não é nossa intenção aqui abordar estudos sobre os efeitos do trabalho escolar nas chamadas comunidades), partimos da definiçáo de Pereira (1967), que nos parece bastante esclarecedora. Comunidade, para ele, é um "agregado humano com residência estável numa certa área geográfica, na qual se concentra ponderável variedade de instituiçóes e associaçóes, capazes de satisfazer aos diversos interesses fundamentais e comuns desse agregado" (PEREIRA, 1967, p. 21). Para o autor, caso essas instituiçóes e associaçóes encontrem-se na área de residência das pessoas, operam como forças centrípetas negativas à existência de uma estrutura comunitária. Para um agregado humano existente em dada área geográfica constituir uma comunidade, certo grau de autossuficiência é imprescindível. É assim que, quanto mais essas instituiçōes se situarem fora do local de residência, mais a lealdade dos moradores se dirigirá para fora dela, fenômeno esse muito característico de áreas residenciais de grandes cidades. Tendo-se a autossuficiência como condição, é mais adequado falar em graus de vida comunitária do que simplesmente em sua presença ou ausência, isto é, alguns agregados humanos possuem mais vida comunitária, outros menos.

Teixeira (1998) define comunidade como o setor da sociedade no qual a escola se situa física e socialmente e por meio do qual recebe o fluxo da cultura 
e das exigências sociais. Situada em um contexto sociopolítico-cultural, a escola recebe dois tipos de influências:

1. Difusas e abrangentes (exercidas pelas tendências educacionais contemporâneas e pelas determinaçóes econômicas, sociais e políticas de cada momento histórico);

2. Específicas e concretas (exercidas pelas políticas públicas de educação, pelas normas do sistema de ensino e pela realidade social, econômica e cultural local), situando-se a comunidade usuária nessa segunda categoria de influências.

Comunidade é uma expressão cujo uso se aplica de forma indevidamente generalizada, de acordo com Mercado (1986), pois a categoria social "comunidade" é concebida como um setor da população delimitado geograficamente, com uma situação econômica e social comum ou, em uma versão mais idealizada, como um agrupamento social com uma identidade comum que lhe permite um funcionamento coletivo alheio à divisão da sociedade em classes. Por outro lado, o setor dessa comunidade que se supóe mais relacionado com a escola é caracterizado homogênea e genericamente como "os pais", que compartiriam interesses comuns com a escola por uma questáo de paternidade, de ambos educarem a mesma criança. No entanto, na verdade, os colocados na categoria "pais" são sujeitos socialmente diferenciados, constituídos nas relações econômicas, sociais, religiosas e políticas de seu próprio âmbito social e do âmbito socioeconômico mais amplo. Eles carregam conflitos que se derivam dessas relaçóes e que permeiam a vida escolar, razão pela qual a relação da escola com seu entorno social não pode reduzir-se à relação com abstratos pais de famílias, definidos em função apenas de seu laço de parentesco com a criança.

Quando se trata da relação escola-comunidade, remete-se a uma concepçâo parcelada da sociedade, em que escola e comunidade aparecem como entidades separadas entre si, estáticas e a-históricas. A comunidade é vista como um todo homogêneo, um conglomerado de gente socialmente indiferenciada. Nessa perspectiva, as determinaçôes sociais que incidem sobre a escola são ignoradas e as relações sociais que caracterizam uma sociedade dividida em classes são obscurecidas.

Ora, a escola não é constituída por agentes ideológica ou politicamente neutros nem homogêneos, nem por vontades individuais que decidem pessoalmente as açôes escolares. Cada escola está imbricada no processo histórico de seu âmbito social imediato e não se pode pensá-la de forma isolada. O contexto sócio-histórico de cada escola permeia e define, com pesos diferentes em diferentes lugares, sua vida diária. 
Geralmente, a formação do pessoal escolar estabelece desenhos de modelos ideais da relação da escola com seu contexto. Para Mercado (1986), não cabe perguntar se a escola se relaciona com seu entorno social, pois a relação, de uma forma ou de outra, sempre existe, como parte orgânica do processo histórico particular de cada lugar. O que cabe é pensar como a vida diária escolar é "continente de processos nos quais se confrontam, se negociam ou se disputam interesses sociais diversos presentes no próprio âmbito local, vinculados a outros que os sustentam" (MERCADO, 1986, p. 54).

Nessa mesma linha, Rockwell (1986) destaca que é necessário evitar a oposição categórica escola-comunidade, como se fossem entidades absolutamente separadas. Para ela, "comunidade é palavra típica na educação e na investigação, que supóe uma abstração e homogeneidade que oculta as divisóes e os mecanismos reais que operam dentro de povoaçóes de todo tamanho" (ROCKWELL, 1986, p. 41). Atualmente, há tal integração no nível econômico, que dificilmente se podem separar as comunidades, especialmente nos grandes centros urbanos, sendo que em todas as regióes existe grande mobilidade das pessoas. Ao conjunto da população, ao mesmo tempo unida e dividida, se sobrepóe a rede escolar. Dificilmente há uma relação unívoca entre cada escola e determinada localidade, pois há muita mobilidade de alunos entre as escolas. Há famílias que procuram escolas mais centrais para seus filhos, por considerá-las melhores; outras buscam as de "mais prestígio", mesmo que mais longe de suas casas. Há escolas que ficam em regióes de passagem, frequentadas por alunos de cursos noturnos que trabalham. Há escolas públicas em zonas privilegiadas, quase só frequentadas por filhos de empregadas domésticas e zeladores. Assim, é difícil falar em comunidade com relação a uma população tão flutuante e desenraizada de seus locais de moradia, principalmente lembrando-se que a palavra comunidade tem relação com comunhão, com qualidade do que é comum.

Azanha (1995) relaciona a questão da integração escola-comunidade com a da participação da comunidade nas decisóes pedagógicas da escola. A esse respeito, ele comenta que não se póe em dúvida que incentivar as comunidades a se interessarem pelas escolas que as servem e a pressioná-las a serem boas escolas é algo inteiramente defensável. Daí a admitir que a situação pedagógica não requeira nenhuma qualificação profissional para a sua condução há uma grande diferença; é mesmo uma desvalorização da formaçáo do professor. Para ele, não é fácil saber se as perspectivas desse encaminhamento são razoáveis e contribuem efetivamente para a solução da crise educacional. O tema da integração lar-escola é, para Azanha (1995), um exemplo paradigmático de que, mesmo sendo politicamente defensável, seus benefícios não estão demonstrados. Ele entende que isso ilustra o poder de banalização de nossas respostas à crise educacional. Age-se como se o simples fato de aproximar instituiçóes interessadas na educação infantojuvenil pudesse levar à superação das deficiências que atribuímos a uma delas, no caso, a escola. 
Talvez, ao pesquisador da educaçáo, valha a pena avançar do conceito de comunidade ao de território, que lhe possibilita ver a educaçáo inter-relacionada a seu contexto, sua cultura e sua dinâmica de funcionamento. O termo território, originário da geografia, não mais se restringe à perspectiva de divisão espacial ou área, mas é compreendido como espaço vivido, ou seja, espaço físico acrescido das disposiçôes e funções dos objetos, das relaçôes sociais, da cultura e das dimensóes simbólicas que tem para seus habitantes. Para Santos (1999; 2000), o conceito de território é útil para a análise social quando tomado como território usado, em permanente mudança e inseparável dos seres humanos que o modificam e são por ele modificados cotidianamente.

\section{Síntese conclusiva}

Importa referir no final deste texto a relevância de pesquisas empíricas que aprofundem os estudos sobre a cultura escolar, processo fundamental à explicação teórico-acadêmica de como funcionam as açōes rotineiras próprias de uma instituição.

As pessoas revelam convicções por meio de hábitos e costumes consolidados. Para não correr o risco de simplificações, ligeireza e superficialidade, cabe ao pesquisador descobrir o que se encontra por trás das açóes e atitudes dos participantes de uma comunidade escolar, analisando-as à luz de referencial teórico substancial.

Com o presente trabalho buscou-se destacar temas relevantes aos estudos sobre a escola. A forma escolar permite compreender características comuns e globais presentes nas práticas escolares. No entanto, tais práticas apresentam nuances particulares, pois cada escola é terreno diferenciado em que subgrupos sociais, que partilham interesses comuns a partir de perspectivas diferentes, conformam a cultura escolar, dentro de determinado tempo, espaço, local e sistema de ensino.

A cultura escolar demonstra a força das tradiçóes e por isso promover mudanças na educação é uma questáo complexa. Igualmente complexa é a investigação sobre como elas ocorrem dentro da escola, no cotidiano. Seu estudo demonstra o difícil equilíbrio entre reprodução e inovação. A percepção de que a reprodução não responde a condiçôes sociais e culturais emergentes e que é preciso buscar inovaçôes constitui ponto nevrálgico para a escola e para seus observadores, pois nesse momento surgem contradiçóes, conflitos e divergências, que podem ser resolvidos ou acirrados, levando a avanços e também a retrocessos. Isso depende do clima organizacional, mais democrático ou mais autoritário, que permite maior ou menor participaçấo e envolvimento das pessoas. E aqui surge a relevância de pesquisas sobre relações interpessoais, liderança e gestão da escola. 
Já é lugar comum dizer-se que a escola não existe em um vácuo social. $\mathrm{O}$ estudo da cultura escolar também permite compreender as relaçóes entre a educação escolar e outras formas sociais de formação dos sujeitos, em especial as relacionadas a formas de exercício do poder na sociedade.

Nesse sentido, é importante compreender as artimanhas usadas nas relaçóes de poder que ocorrem entre a equipe escolar, o poder público e os usuários. Lembrando que esses raramente correspondem à imagem de uma comunidade uniforme, geograficamente localizada e economicamente homogênea.

A descrição da situação escolar em campo, frente a frente com os atores institucionais, tem imensa importância nesse sentido porque somente o acúmulo sistemático de informaçóes permitirá compor um quadro compreensivo do papel da instituição-escola no panorama social, ponto de partida para um esforço coletivo de explicação e reformulação.

Entender os conceitos e concepçôes aqui apresentados requer que se estude o que ocorre dentro da escola em relação ao que acontece no seu exterior, em um contexto de codeterminaçóes recíprocas. As consequências são importantes, como, por exemplo, a de evitar a circulação de acusaçóes entre governo, escola, professores e pais, para explicar a baixa qualidade da educaçáo.

\section{Notas}

1 É obra clássica sobre o tema: Bourdieu \& Passeron (1975).

2 Em especial, destaco as seguintes obras: Certeau (1995; 2001), Certeau et al. (2000) e Williams (2000).

\section{Referências}

AZANHA, J.M.P. Educação: temas polêmicos. São Paulo: Martins Fontes, 1995.

BARROSO, J. Cultura, cultura escolar, cultura de escola. Princípios Gerais da Administração Escolar, v. 1, 2012. Disponível em: <http://acervodigital.unesp.br/ handle/123456789/65262>. Acesso em: 19 jun. 2017.

BEISIEGEL, C.R. A qualidade do ensino na escola pública. Brasília: Líber Livro, 2005.

Bourdieu, P.; Passeron, J.-C. A reproduçâo: elementos para uma teoria do sistema de ensino. Rio de Janeiro: Francisco Alves, 1975.

BRUNET, L. Clima de trabalho e eficácia na escola. In: NÓVOA, A. (Coord.). As organizaçôes escolares em análise. Lisboa: Dom Quixote, 1999. p. 123-140.

CERTEAU, M. A cultura no plural. Campinas: Papirus, 1995.

. A invenção do cotidiano: artes de fazer. Petrópolis: Vozes, 2001. v. 1. 
CERTEAU, M.; GIARD, L.; MAYOL, P. A invenção do cotidiano: morar, cozinhar. Petrópolis: Vozes, 2000.

ENGUITA, M.F. Da democratização ao profissionalismo. In: FERREIRA, N.S.C. (Org.). Supervisáo educacional para uma escola de qualidade. São Paulo: Cortez, 2003. p. 97-123.

FORQUIN, J.-C. Escola e cultura: as bases sociais e epistemológicas do conhecimento escolar. Porto Alegre: Artmed, 1993.

GIMENO SACRISTÁN, J. Poderes instáveis em educação. Porto Alegre: Artmed, 1999.

HARGREAVES, A. Os professores em tempo de mudança: o trabalho e a cultura dos professores na idade pós-moderna. Lisboa: McGraw-Hill, 1998.

MAFRA, L.A. A Sociologia dos estabelecimentos escolares: passado e presente de um campo de pesquisa em re-construção. In: ZAGO, N.; CARVALHO, M.P.; VILELA, R.A.T. (Orgs.). Itinerários de pesquisa: perspectivas qualitativas em Sociologia da Educação. Rio de Janeiro: DP\&A, 2003. p. 109-136.

MERCADO, R. Una reflexión crítica sobre la noción "escuela-comunidad". In: ROCKWELL, E.; MERCADO, R. La escuela, lugar del trabajo docente: descripciones y debates. México: Centro de Investigación y de Estudios Avanzados del IPN, 1986. p. 47-53.

NÓVOA, A. Para uma análise das instituiçóes escolares. In: (Coord.). As organizaçôes escolares em análise. Lisboa: Dom Quixote, 1999. p. 13-43.

PEREIRA, L. A escola numa área metropolitana. São Paulo: Pioneira-Edusp, 1967.

POPKEWITZ, T.S. Reforma educacional, uma política sociológica: poder e conhecimento em educação - A reforma educacional como um discurso da organização e regulamentação social: as propostas da década de 80. Porto Alegre: Artmed, 1997. p. 147-177. Cap. 5.

ROCKWELL, E. 1 - De huellas, bardas y veredas: una historia cotidiana en la escuela. 2 - Acercamiento a la realidad escolar. In: ROCKWELL, E.; MERCADO, R. La escuela, lugar del trabajo docente: descripciones y debates. México: Centro de Investigación y de Estudios Avanzados del IPN, 1986. p. 9-45.

SANTOS, M. O território e o saber local: algumas categorias de análise. Cadernos IPPUR, ano XIII, n. 2, p. 15-26, 1999.

Território e sociedade: entrevista com Milton Santos. São Paulo: Ed. Fundação Perseu Abramo, 2000.

SARMENTO, M.J. A vez e a voz dos professores: contributo para o estudo da cultura organizacional da escola primária. Porto: Porto, 1994.

SCHEIN, E.H. Organization culture and leadership. San Francisco: Jossey-Bass, 1985.

TEIXEIRA, L.H.G. Cultura organizacional e projeto de mudança em escolas públicas: um estudo de escolas da rede estadual de Minas Gerais. Tese (Doutorado em Educação)Universidade Estadual de Campinas, Campinas, 1998. 
Tragtenberg, M. A escola como organização complexa. Maurício Tragtenberg, 2016. Disponível em: shttp://mauriciotragtenberg.blogspot.com.br/2016/10/a-escola-comoorganizacao-complexa.html . Acesso em: 2 dez. 2017.

VIÑAO FRAGO, A. Por una historia de la cultura escolar: enfoques, cuestiones, fuentes. In: ALMUIÑA FERNÁNDEZ, C.; ARBAT, T.C.; ARTOLA, M.; MARTÍN, J.A.M.; MOLINA, M.G.; TAVERA, S.; VILLARES, R.; VIÑAO FRAGO, A.; BERAMENDI, J.G.; GUERENAA, J.-L.; SERRANO, C.S. (Orgs.). Culturas y civilizaciones: III Congreso de la Asociación de Historia Contemporánea. Valladolid: Universidad de Valladolid, 1998.

VINCENT, G.; LAHIRE, B.; THIN, D. Sobre a história e a teoria da forma escolar. Educą̧ão em Revista, Belo Horizonte, n. 33, p. 7-47, 2001.

WARDE, M.J. Apresentação: a educação escolar no marco das novas políticas educacionais. In: _. (Org.). In: SEMINÁRIO INTERNACIONAL NOVAS POLÍTICAS EDUCACIONAIS: CRÍTICAS E PERSPECTIVAS, 2., São Paulo, 1998. São Paulo: PUC-SP, 1998.

WELLER, S. The structure of formally organized socialization settings. In: BRIM, O.; WELLER, S. (Eds.). Socialization and childhood. Nova York: Wiley and Sons, 1966. p. 53-115.

WILLIAMS, R. Cultura. São Paulo: Paz e Terra, 2000. v. 2.

Recebido em 20 de julho de 2017.

Aceito em 17 de janeiro de 2018. 